\title{
Diffuse hepatic hemorrhage in a patient undergoing emergency conventional coronary artery bypass surgery following cardiopulmonary resuscitation
}

\author{
Ayhan Muduroglu ${ }^{1}$, Mustafa Cagdas Cayir ${ }^{2}$ and Ahmet Yuksel ${ }^{2 *}$ \\ ${ }^{1}$ Department of Cardiovascular Surgery, Bursa Yildırım Doruk Hospital, Bursa, Turkey \\ ${ }^{2}$ Department of Cardiovascular Surgery, Bursa State Hospital, Bursa, Turkey
}

\begin{abstract}
A 71-year-old male patient was admitted with a diagnosis of acute myocardial infarction, he underwent an urgent coronary angiography and stent implantation to a totally occluded circumflex coronary artery. During the percutaneous coronary intervention, cardiac arrest occurred and a short-lived and successful mechanical and medical cardiopulmonary resuscitation was applied. Once a satisfactory cardiac rhythm and arterial blood pressure were obtained, the patient underwent coronary artery bypass surgery on an emergency basis. During the operation, a high volume of intraabdominal hemorrhage secondary to hepatic injury was observed following additional exploratory laparotomy. We performed perihepatic packing for diffuse hepatic hemorrhage, since there was no particular focus of bleeding or rupture in the liver. In spite of accurate and sufficient fluid and blood product replacement, the patient died on account of hypovolemic shock. This report highlights the possibility of diffuse hepatic hemorrhage secondary to liver injury related to cardiopulmonary resuscitation.
\end{abstract}

\section{Introduction}

Hepatic injury and hemorrhage following manual cardiac compression as one of major components of cardiopulmonary resuscitation (CPR) is an unusual condition with an incidence of $\sim 0.6$ $3 \%$, and is the most frequent intraabdominal complication related to CPR. Although hepatic injury and hemorrhage following CPR is very rare, it is associated with high mortality rate when occur [1-5]. Here, we presented a case report of diffuse hepatic hemorrhage secondary to liver injury in a patient undergoing emergency conventional coronary artery bypass grafting $(\mathrm{CABG})$ operation following CPR.

\section{Case presentation}

A 71 year-old male was treated with aspirin, clopidogrel and low molecular weight heparin with a diagnosis of acute myocardial infarction (MI) in another health facility, and was referred to our hospital. Physical examination and routine biochemical tests were not revealed any significant finding. The patient presenting with MI had undergone a coronary stent implementation to a totally occluded circumflex coronary artery. Cardiac arrest occurred during the procedure, and systemic heparin and intracoronary tirofiban were administered to the patient. After a successful CPR, the patient was taken to CABG operation on an emergency basis. With cardiopulmonary bypass (CPB) support, CABGx3 operation was performed on beating heart. During the operation, the decrease in venous flow and fall of hematocrit level to $12 \%$ were compensated by blood product transfusion and crystalloid fluid replacements. The patient was weaned from CPB support smoothly without any inotropic drug support. Nevertheless, hypovolemic shock developed in a short time and the fall of hematocrit level continued. Upon observing abdominal distension, intraabdominal hemorrhage was anticipated, emergency exploratory laparotomy was performed, and $2500 \mathrm{ml}$ of fresh blood was observed in the peritoneal cavity. The patient was reheparinized and connected to the extracorporeal circulation, and then intraabdominal blood volume was retrieved into the extracorporeal circulation. There was no particular focus of bleeding or rupture in the liver. Instead, the hepatic capsule was almost completely torn, and diffuse and profuse bleeding was observed on the whole surface of the liver (Figure 1). Perihepatic packing was performed, extracorporeal circulation was urgently terminated, and heparin was neutralized with protamin. Seven units of erythrocyte suspension, 5 units of fresh frozen plasma, $675 \mathrm{mg}$ of calcium gluconate and $1 \mathrm{gr}$ of tranexamic acid were rapidly infused. The excessive bleeding could not be controlled and the patient died due to hypovolemic shock.

\section{Discussion}

Celio [6] and Reagan et al. [7] reported successful open cardiac massage with thoracotomy in 1956. Four years later, Kouwenhoven et al. [8] described the closed-chest cardiac massage and postulated that patients recovered faster with this technique. Other reports which demonstrating the efficiency of the closed-chest technique also published in the ensuing three years, nonetheless Baringer et al. [9] and Portal et al. [10] reported some complications related to the closed technique such as rib fracture, hemothorax, hemopericardium, hepatic injury and bone marrow embolism.

Correspondence to: Dr. Ahmet Yuksel, Department of Cardiovascular Surgery, Bursa State Hospital, Tophane Street, 16041, Bursa, Turkey, Tel: +90 505 8460753; Fax: +90 224 2132993; E-mail: ahmetyuksel1982@mynet.com

Key words: hepatic injury, hepatic hemorrhage, cardiopulmonary resuscitation

Received: April 22, 2017; Accepted: May 25, 2017; Published: May 29, 2017 


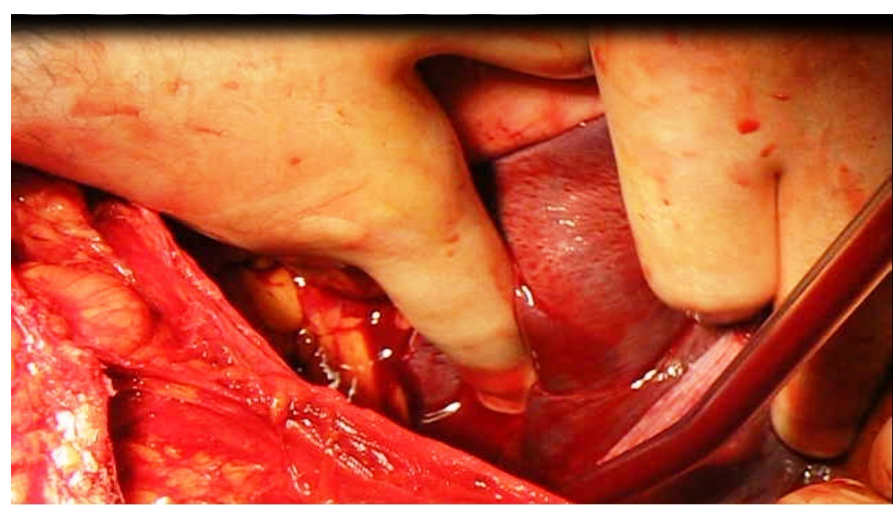

Figure 1. Intraoperative view of diffuse hepatic hemorrhage

There is no significant difference between the definition of resuscitation made a half century ago and the recommendations pertaining latest updated guidelines. It is advised by the international guidelines that the pressure should be applied only on the sternum to avoid complications like rib fractures and soft tissue injuries [11-13].

Complications related to CPR are well known since the very day it was first defined and is present in the literature. Most frequently rib fracture (in postmortem studies 25-50\%), sternal fracture, chest wall hematoma, pneumothorax, cardiac contusion, less frequently thoracic aorta rupture, diaphragmatic rupture and gastric perforation are seen as complications of CPR. Very rarely hepatic injuries can be contemplated $[14,15]$. Hepatic injury related to CPR is very rare but carries a high mortality rate [1-5]. Meron et al. [1] in their study spanning 14.5 years among 2558 cardiac arrest cases found $15(0.06 \%)$ cases of major hepatic injuries (11 rupture, 4 hemorrhage and hematoma). Six of them were detected at postmortem period, of the surviving 9 patients six were treated surgically, the other 3 medically. One patient from each group has survived (mortality rate of $87 \%$ ). Numerous hypotheses have been advocated for explaining the causes of hepatic injury. According to Meron et al. [1] it may be due to improper employment of CPR, on the other hand Kunstyr et al. [2] have claimed that blunt trauma, vibration of the sternal saw or piercing traumas due to chest tube insertion combined with the augmenting effect of hepatic congestion can lead to hepatic injury. Krischer et al. [14] have postulated that $73 \%$ of hepatic injury cases are due to rib fractures. Becit et al. [16] reported that the injury or the hemorrhage could be spontaneous.

A typical post-CPR hepatic injury is located on the left of the falciform ligament and usually it is due to the forceful pressure exerted on the hand placed on the xyhoid [3]. According to Adler et al. [17] the features of hepatic injury are deteriorating hypovolemic shock in a patient on anticoagulants with enlargement of the abdominal circumference. Hachiro et al. [18] have reported a patient receiving ticlodipin with pericardial tamponade after CPR in the absence of rib and sternal fracture.

In order to minimize CPR complications, mechanical devices (the LUCAS device, etc) have been developed but in pilot study no difference was found to conventional method regarding efficiency or complications [19].

In major and continuing hepatic hemorrhage due to injury for hemostasis the hepatoduodenal ligament can be encircled with a Penrose (pringle method) and temporarily clamped. Meanwhile, treatment alternatives should be considered and necessary medications (antithrombin III, protamin, fibrinogen, tranexamic acid, platelet suspension, whole fresh blood, fresh frozen plasma) can be administered. If oozing is persisting perihepatic packing may be employed (de-packing can be done 48-72 hours after stabilization) [20].

In this present case, our patient received both anticoagulant and antiaggregant agents, and sustained hepatic congestion due to the cardiac arrest, CPR had to be performed on the angiography table in suboptimal conditions, and he was a high-risk patient in terms of hepatic injury and hemorrhage because of the being subject of exposed to extracorporeal circulation. It might not be possible to avert all the risks but minimizing could well be. The resuscitation should be applied on the mid portion of the sternum and in a perpendicular angle, sternum should be depressed $5 \mathrm{~cm}$, over ventilation avoided. At easy accessible institutions, the access to antithrombin III, fibrinogen, platelet suspension, fresh whole blood, and routine availability of cell saver and rapid blood transfusion systems, and lastly multidisciplinary team organization are of utmost importance. Almost as important is physicians dealing with such patients (emergency physician, cardiologist, surgeon, etc.) should always bear in mind the possibility of hepatic injury. In order to avoid, identify and treat this kind of rare condition, the first requirement is to anticipation and awareness of such rare complications.

\section{References}

1. Meron G, Kurkciyan I, Sterz F, Susani M, Domanovits H, Tobler K, et al. (2007) Cardiopulmonary resuscitation-associated major liver injury. Resuscitation 75: 445453. [Crossref]

2. Kunstyr J, Tosovsky J, Korinek J, Stritesky M (2008) Hepatic tear as an elusive cause of hemoperitoneum complicating cardiac surgery. Interact Cardiovasc Thorac Surg 7: 435-436. [Crossref]

3. Martin FJG, Ordonez AP, Tarrio IC, Campillo BM (2009) Liver laceration caused by cardiopulmonary resuscitation manoeuvres. Emergencias 21: 148-150.

4. Kaplon-Cieslicka A, Kosior DA, Grabowski M, Rdzanek A, Huczek Z, et al. (2013) Coronary artery dissection, traumatic liver and spleen injury after cardiopulmonary resuscitation - a case report and review of the literature. Arch Med Sci 9: 1158-1161. [Crossref]

5. Beydilli H, Balci Y, Erbas M, Acar E, Isik S, et al. (2016) Liver laceration related to cardiopulmonary resuscitation. Turk J Emerg Med 16: 77-79. [Crossref]

6. Celio A (1956) Cardiac arrest associated with coronary occlusion: successful resuscitation. J Int Coll Surg 25: 299-305.

7. Reagan LB, Young KR, Nicholson JW (1956) Ventricular defibrillation in a patient with probable acute coronary occlusion. Surgery 39: 482-486. [Crossref]

8. Kouwenhoven WB, Jude JR, Knıckerbocker GG (1960) Closed-chest cardiac massage. JAMA 173: 1064-1067. [Crossref]

9. Barınger JR, Salzman EW, Jones WA, Frıedlıch AL (1961) External cardiac massage $N$ Engl J Med 265: 62-65. [Crossref]

10. Portal RW, Robinson BF, Leatham AG (1963) Notes on cardiac resuscitation, including external cardiac massage. $\mathrm{Br}$ Med $J$ 1: 636-641.

11. International Liaison Committee on Resuscitation (2005) 2005 International consensus on cardiopulmonary resuscitation and emergency cardiovascular care science with treatment recommendations. Part 2: adult basic life support. Resuscitation 67: 187-201.

12. ECC Committee, Subcommittees and Task Forces of the American Heart Association. 2005 American Heart Association guidelines for cardiopulmonary resuscitation and emergency cardiovascular care. Circulation 112(24 Suppl): IV1-203.

13. Handley AJ, Koster R, Monsieurs K, Perkins GD, Davies S, Bossaert L (2005) European Resuscitation Council guidelines for resuscitation 2005. Section 2. Adult basic life support and use of automated external defibrillators. Resuscitation 67(Supp1 1): $\mathrm{S} 7-23$.

14. Krischer JP, Fine EG, Davis JH, Nagel EL (1987) Complications of cardiac resuscitation. Chest 92: 287-291. [Crossref] 
Muduroglu A (2017) Diffuse hepatic hemorrhage in a patient undergoing emergency conventional coronary artery bypass surgery following cardiopulmonary resuscitation

15. Smekal D, Lindgren E, Sandler H, Johansson J, Rubertsson S (2014) CPR-related injuries after manual or mechanical chest compressions with the LUCASâ, $\notin$ device: a multicentre study of victims after unsuccessful resuscitation. Resuscitation 85: 17081712. [Crossref]

16. Becit N, Ceviz M, Koçak H, Polat KY (2004) Surgical treatment in a patient with multipl systemic complications of prostethic aortic valve endocarditis. Heart Surg Forum 8: E52-54.

17. Adler SN, Klein RA, Pellecchia C, Lyon DT (1983) Massive hepatic hemorrhage associated with cardiopulmonary resuscitation. Arch Intern Med 143: 813-814.
18. Hachiro Y, Okada H, Hayakawa T, Matsubara I, Maekawa K, Tanaka T (2000) Cardiac tamponade secondary to cardiopulmonary resuscitation in a patient receiving antiplatelet therapy. Am J Emerg Med 18: 836-837.

19. Smekal D, Johansson J, Huzevka T, Rubertsson S (2009) No difference in autopsy detected injuries in cardiac arrest patients treated with manual chest compressions compared with mechanical compressions with the LUCAS device -- a pilot study. Resuscitation 80: 1104-1107.

20. Girgin S, Gedik E, Taçyildiz IH (2006) [Evaluation of surgical methods in patients with blunt liver trauma]. Ulus Travma Acil Cerrahi Derg 12: 35-42. [Crossref]

Copyright: $(\mathbb{C} 2017$ Muduroglu A. This is an open-access article distributed under the terms of the Creative Commons Attribution License, which permits unrestricted use, distribution, and reproduction in any medium, provided the original author and source are credited. 